\title{
PRÁTICAS MATERNAS E USO DE TERAPIAS ALTERNATIVAS NO CUIDADO DA CRIANÇA
}

\author{
Karina Jullyana de Melo Brondani ${ }^{1}$, Rosângela Aparecida Pimenta Ferrari ${ }^{2}$, Alexandrina Aparecida Maciel \\ Cardelli ${ }^{3}$, Mauren Teresa Grubisich Mendes Tacla², Flávia Genovesi Fançoso ${ }^{4}$, José Carlos Dalmas ${ }^{5}$
}

\begin{abstract}
RESUMO: Objetivo: analisar o cuidado da criança e uso de terapias alternativas pelas mães nos primeiros 42 dias pós-parto. Método: pesquisa quantitativa descritiva transversal realizada em maternidade pública de baixo risco e visita domiciliar aos 42 dias pós-parto, entre julho de 2013 e janeiro de 2014, em Londrina-PR. Utilizou-se o Teste de Exato de Fischer e Qui-Quadrado com intervalo de confiança de $95 \%$. Resultado: entre as 357 puérperas, $50,7 \%$ com idade $\leq 24$ anos, $69,2 \%$ multíparas, $75,4 \%$ escolaridade $\geq 8$ anos e $49 \%$ renda $\geq 2$ salários mínimos. A terapia complementar foi indicada predominantemente por avós, utilizada no banho da criança $(97=27,2 \%)$, coto umbilical $(143=39,9 \%)$, conjuntivite $(108=81 \%)$ e icterícia $(56=34,6 \%)$. A classe social foi significativa $(p=0,005)$ com a faixa etária, escolaridade, renda e uso de chás. Conclusão: as práticas maternas se mantiveram entre as gerações, algumas indiscriminadamente, sendo necessário que a equipe de saúde previna agravos e promova saúde considerando os aspectos culturais familiares.

DESCRITORES: Saúde da criança; Enfermagem transcultural; Cuidados de enfermagem; Enfermagem pediátrica; Promoção da saúde.
\end{abstract}

\section{MATERNAL PRACTICES AND THE USE OF ALTERNATIVE THERAPIES IN THE CARE OF THE CHILD}

ABSTRACT: Objective: to analyze the care of the child and the use of alternative therapies by mothers in the first 42 days postpartum. Method: quantitative descriptive cross-sectional study carried out in a low-risk public maternity ward, with a home visit at 42 days postpartum, between July 2013 and January 2014, in Londrina-PR. The Fischer Exact and Chi-Square Tests were used considering a $95 \%$ confidence interval. Results: among the 357 puerperal women, $50.7 \%$ were aged $\leq 24$ years, $69.2 \%$ multiparous, $75.4 \%$ had $\geq 8$ years of schooling and $49 \%$ an income $\geq 2$ minimum salaries. Complementary therapy was predominantly suggested by the grandmothers, used in the child's bath $(97=27.2 \%)$, on the umbilical stump $(143=39.9 \%)$, for conjunctivitis $(108=81.0 \%)$ and for jaundice $(56=34.6 \%)$. The social class was significant $(p=0.005)$ with age, education, income and use of teas. Conclusion: maternal practices are maintained between generations, some indiscriminately, with it being necessary for the health team to prevent injuries and promote health considering the cultural aspects of the family.

DESCRIPTORS: Child health; Cross-cultural nursing; Nursing care; Pediatric nursing; Health promotion.

\section{PRÁCTICAS MATERNAS Y USO DE TERAPIAS ALTERNATIVAS EN EL CUIDADO AL NIÑO}

RESUMEN: Objetivo: analizar el cuidado al niño y el uso de terapias alternativas por las madres en los primeros 42 días tras el parto. Método: investigación cuantitativa descriptiva transversal que ocurrió en maternidad pública de bajo riesgo y visita domiciliaria a los 42 días tras el parto, entre julio de 2013 y enero de 2014, en Londrina-PR. Se utilizaron el Test Exacto de Fischer y el Chi Cuadrado con intervalo de confianza de $95 \%$. Resultado: entre las 357 puérperas, 50,7\% presentaban edad $\leq 24$ años, 69,2\% eran multíparas, 75,4\% tenían escolaridad $\geq 8$ años y $49 \%$, renta $\geq 2$ salarios mínimos. La terapia complementaria fue indicada predominantemente por los abuelos, utilizada en el baño del niño $(97=27,2 \%)$, ombligo $(143=39,9 \%)$, conjuntivitis $(108=81 \%)$ e ictericia $(56=34,6 \%)$. La clase social fue significativa $(p=0,005)$ así como la franja etaria, escolaridad, renta y uso de tes. Conclusión: las prácticas maternas se mantuvieron entre las generaciones, algunas de modo indiscriminado, siendo necesario que el equipo de salud haga la prevención de agravios y promueva salud considerándose los aspectos culturales familiares.

DESCRIPTORES: Salud del niño; Enfermería transcultural; Cuidados de enfermería; Enfermería pediátrica; Promoción de la salud.

${ }^{1}$ Enfermeira. Especialista em Enfermagem em Saúde da Criança. Universidade Estadual de Londrina. Londrina, PR, Brasil. ${ }^{2}$ Enfermeira. Doutora em Saúde da Criança e do Adolescente. Docente de Enfermagem da Universidade Estadual de Londrina. Londrina, PR, Brasil.

${ }^{3}$ Enfermeira. Doutora em Saúde da Mulher e Gênero. Docente de Enfermagem da Universidade Estadual de Londrina. Londrina, PR, Brasil.

${ }^{4}$ Enfermeira. Mestre em Enfermagem. Universidade Estadual de Londrina. Londrina, PR, Brasil.

${ }^{5}$ Matemático. Doutor em Matemática. Docente da Universidade Estadual de Londrina. Londrina, PR, Brasil.

Autor Correspondente:

Rosângela Aparecida Pimenta Ferrari

Universidade Estadual de Londrina

Av. Robert Koch, 60 - 86038-350 - Londrina, PR, Brasil

E-mail: ropimentaferrari@uel.br
Recebido: 24/07/2017

Finalizado: $22 / 08 / 2018$ 


\section{INTRODUÇÃO}

O conceito de cultura pode ser definido como valores, crenças e práticas compartilhadas, apreendidas ao longo das gerações. Representa uma teia de signos a serem decifrados, em que a visão do mundo, a etnia, a história, a religião e outros fatores influenciam direta e indiretamente as práticas de uma comunidade e perduram no tempo ${ }^{(1)}$.

A prática popular toma grandes dimensões, tornando-se aliada dos cuidados de saúde no período gestacional e no puerpério. Em ambas as fases, ocorrem transformações no corpo e na mente da mulher, afetando o seu cotidiano e o de sua família. É comum que nestes momentos ocorram compartilhamento de informações com os parentes, grupo social ou entes mais próximos, principalmente quando se trata de uma primeira gestação, quando as dúvidas e preocupações se tornam mais presentes e se manifesta a confiança nos conhecimentos de outras mulheres que já passaram pelo mesmo processo ${ }^{(2-3)}$.

Entre os fatores que levam as pessoas a aderirem às Terapias Complementares (TC), destacam-se: a influência de pessoas mais próximas e que passaram por situação similar; a falta de confiança na medicina convencional; situação financeira insuficiente para arcar com o tratamento proposto pela equipe de saúde, assim como a ausência de vínculo com essa equipe. Este último fator leva a puérpera a ocultar da equipe de saúde o uso de terapias alternativas e a adiar o tempo de procura por um serviço de saúde(4).

Diante das práticas populares, em especial as relacionadas ao cuidado com o recém-nascido, é importante detectar a nocividade que as TC podem trazer, a fim de corrigi-las. Tais intervenções serão efetivas se houver vínculo com o profissional para estabelecer uma relação de confiança com a puérpera e a família, viabilizando a adesão aos conhecimentos adquiridos e a substituição das práticas errôneas com base na compreensão dos riscos, vantagens e desvantagens para a saúde da criança ${ }^{(4-6)}$.

O presente estudo teve como objetivo analisar o cuidado da criança e uso de terapias alternativas pelas mães nos primeiros 42 dias pós-parto. Pois, se cada indivíduo vive em um determinado contexto e este tem influência em suas ações, incluindo o cuidado à saúde, é necessário compreender o entendimento da família sobre o processo saúde-doença, de forma a acrescentar o que falta para a realização eficaz do cuidado e corrigir práticas que colocam em risco a saúde dos seus membros, visando o desenvolvimento saudável de forma integral ${ }^{(7)}$.

\section{MÉTODO}

Trata-se de estudo quantitativo descritivo transversal com mulheres que realizaram parto em maternidade pública, referência para gestação de risco habitual e intermediário, que atende cerca de 80\% dos partos pelo Sistema Único de Saúde, em Londrina-PR, Brasil.

Para obter a população de estudo, realizou-se cálculo amostral a partir dos 3.415 partos do ano anterior (2012), margem de erro de 5\% e nível de confiança de 95\%, resultando em 358 participantes. Houve uma exclusão, devido à doação de uma criança, totalizando 357 puérperas.

Para a coleta de dados, os pesquisadores abordaram diariamente as mulheres na maternidade até alcançar o $\mathrm{n}$ amostral, utilizando formulário com questões semiestruturadas como dados sociodemográficos, assistência pré-natal, trabalho de parto, parto, alojamento conjunto e orientações para alta, cuidado puerperal após alta, cuidados e práticas com o bebê no domicílio. A inclusão foi residir na zona urbana, ser gestante de risco habitual e intermediário e ser capaz de compreender e consentir sua participação no estudo.

A pesquisa compreendeu quatro etapas, de julho de 2013 a fevereiro de 2015: a primeira, na maternidade, em prontuários, entrevista, Cartão da Gestante e Cartão da Criança; a segunda, observação do atendimento no Ambulatório da maternidade uma semana pós-parto; a terceira, visita domiciliar (VD) 42 dias pós-parto para identificar a assistência recebida na maternidade, no serviço de saúde após alta, evolução e intercorrência puerperal, cuidados com o bebê; e última, VD um ano pósparto. O presente estudo se refere aos dados da primeira e segunda etapa, no período de julho de 2013 a janeiro de 2014. 
As variáveis deste estudo se referem à caracterização materna e da criança: faixa-etária, escolaridade, situação conjugal, paridade, ocupação, renda, via de parto e peso ao nascer; ao cuidado materno à criança pós-parto quanto à higiene corporal, ocular e umbilical; icterícia, dermatites e cólica abdominal; à caracterização dos orientadores das mães na maternidade (profissionais da maternidade) e no domicílio (familiares, etc.) para o auxílio no cuidado da criança. Os dados foram armazenados e processados no programa SPSS ${ }^{\circledR}$. Para análise, utilizou-se o Teste de Exato de Fischer e Qui-Quadrado, considerando nível de confiança de $95 \%, p=0,005$.

A pesquisa foi autorizada pela Autarquia Municipal e aprovada pelo Comitê de Ética da Universidade Estadual de Londrina, no120.13/UEL.

\section{- RESULTADOS}

A Tabela 1 mostra que, das 357 puérperas atendidas na maternidade, 50,7\% (181) eram jovens $(\leq 24$ anos) e $75,4 \%$ (269) com $\geq 8$ anos de estudo, 58,5\% (209) com ocupação remunerada, 81,2\% (290) classe social CD e $84 \%$ (300) com companheiro. A multiparidade totalizou 69,2\% (215).

Para $74,5 \%$ (266) o parto foi vaginal e quase a totalidade (351=98,3\%) dos recém-nascidos apresentou peso adequado para a idade gestacional. O apoio familiar ocorreu para quase a totalidade $(349=97,8 \%)$, sendo considerada uma das facilidades $(271=70,3 \%)$, seguido do comportamento tranquilo do bebê $(83=23,2 \%)$.

As dificuldades estavam relacionadas ao bebê como choro frequente $(65=18,2 \%)$, sono conturbado $(64=17,9 \%)$ e problemas com amamentação $(48=13,4 \%)$. Outras dificuldades foram a falta de tempo para realizar outras atividades que não diziam respeito ao bebê $(99=27,7 \%)$ e mudança de comportamento dos outros filhos $(64=17,9 \%)$.

Tabela 1 - Variáveis socioeconômicas, obstétricas, rede de apoio materno, facilidades e dificuldades no cuidado da criança nos primeiros 42 dias pós-parto. Londrina, PR, Brasil, 2013 (continua)

\begin{tabular}{lcc} 
Variáveis & $\mathbf{n}$ & $\mathbf{\%}$ \\
& $\mathbf{3 5 7}$ & $\mathbf{1 0 0}$ \\
\hline Faixa etária (em anos) & & \\
\hline$\leq 24$ & 181 & 50,7 \\
\hline$\geq 25$ & 176 & 49,3 \\
\hline Escolaridade (anos de estudo) & 88 & 24,6 \\
\hline$\leq 7$ & 269 & 75,4 \\
\hline 8 e mais & & \\
\hline Situação conjugal & 88 & 15,9 \\
\hline Sem companheiro & 300 & 84 \\
\hline Com companheiro & & \\
\hline Paridade & 142 & 39,7 \\
\hline Primípara & 215 & 69,2 \\
\hline Multípara & & \\
\hline Ocupação materna & 148 & 41,4 \\
\hline Remunerada & 209 & 58,5 \\
\hline Não remunerada & \multicolumn{1}{l}{} \\
\hline Renda Mensal (em salário mínimo) & 166 & 46,5 \\
\hline$<2$ & 175 & 49 \\
\hline 2 e mais & & \\
\hline
\end{tabular}




\begin{tabular}{|c|c|c|}
\hline \multicolumn{3}{|l|}{ Classe Social** } \\
\hline $\mathrm{AB}$ & 67 & 18,8 \\
\hline $\mathrm{CD}$ & 290 & 81,2 \\
\hline \multicolumn{3}{|l|}{ Via de parto } \\
\hline Vaginal & 266 & 74,5 \\
\hline Cirúrgico & 91 & 25,4 \\
\hline \multicolumn{3}{|l|}{ Peso ao nascer (em gramas) } \\
\hline$<2500$ & 6 & 1,7 \\
\hline$\geq 2500$ & 351 & 98,3 \\
\hline \multicolumn{3}{|l|}{ Rede apoio no retorno para casa } \\
\hline Sim & 349 & 97,8 \\
\hline Não & 8 & 2,2 \\
\hline \multicolumn{3}{|l|}{ Adaptação no período foi tranquila } \\
\hline Sim & 169 & 47,3 \\
\hline Não & 188 & 52,7 \\
\hline \multicolumn{3}{|l|}{ Facilidades no cuidado da criança } \\
\hline Apoio familiar & 251 & 70,3 \\
\hline Bebê pouco choroso & 83 & 23,2 \\
\hline Experiência prévia & 23 & 6,4 \\
\hline \multicolumn{3}{|l|}{ Dificuldades no cuidado da criança } \\
\hline Falta de tempo para atividades além do cuidado da criança & 99 & 27,7 \\
\hline Choro excessivo do bebê & 65 & 18,2 \\
\hline Sono do bebê era perturbado & 64 & 17,9 \\
\hline Ciúmes dos outros filhos & 64 & 17,9 \\
\hline Problemas relacionados à amamentação & 48 & 13,4 \\
\hline Bebê apresentou cólica abdominal & 17 & 4,8 \\
\hline
\end{tabular}

*Valor referente ao salário brasileiro do ano 2013, R\$ 678,00, decreto $n^{\circ} 7,872 / 2012$; $^{*}$ Classificação de classe social segundo posse de bens proposta pela Associação Brasileira de Estudos Populacionais (ABEP) ${ }^{(8)}$

O banho do recém-nascido foi realizado com componentes alternativos $(97=27,2 \%)$, sendo chá de folhas $(54=15,1 \%)$ como camomila, arruda, folha de tomate, folha de mandioca e erva-doce. Outros componentes $(43=12,1 \%)$ utilizados foram o leite materno, amido de milho, álcool, açúcar, sal e telha virgem (Tabela 2).

Quanto à higiene do coto umbilical, quase a totalidade das mães o realizou utilizando água e sabão (214=59,9\%), mas 39,9\% (143) com outros componentes, sendo 28\% (100) com álcool a 70\% e 11,9\% (43) outras substâncias (soro fisiológico, fumo, moedas, faixas e óleos).

O manejo da conjuntivite ocular ocorreu em 37,2\% (133) dos bebês, utilizando-se colírios (30,8\%) e $81 \%$ (108) componentes alternativos, 39,9\% (43) leite materno.

Do total das mães, 45\% (161) referiu que seu bebê apresentou icterícia e 25,4\% (41) foi tratado com fototerapia na maternidade e 39,7\% (64) banho de sol, mas 34,6\% (56) utilizaram tratamentos alternativos como banho de picão (43=26,6\%) com administração oral (9=6,1\%).

O uso múltiplo de pomadas para prevenir assaduras pelas mães totalizou $65 \%$ (233), sendo 59,6\% (139) à base de vitaminas A, D, B5 e E, 57\% (133) substâncias adstringentes (óxido de zinco) e 30\% (70) a base de antimicrobianos (nistatina, cetoconazol, neomicina, etc). A cólica abdominal foi identificada em $61,3 \%$ (219) das crianças e 52,5\% (115) usaram mais de um tipo de chá para seu alívio, camomila $(78=67,8 \%)$ e erva-doce $(65=56,5 \%)$. 
Tabela 2 - Cuidados maternos com a higiene corporal e manejo das patologias comuns nos primeiros 42 dias pós-parto. Londrina, PR, Brasil, 2013

\begin{tabular}{|c|c|c|}
\hline \multirow[t]{2}{*}{ Cuidados maternos } & $\mathbf{n}$ & $\%$ \\
\hline & 357 & 100 \\
\hline \multicolumn{3}{|l|}{ Banho realizado pela mãe } \\
\hline Componente utilizado no banho & 341 & 95,5 \\
\hline Água e sabão & 260 & 72,8 \\
\hline Alternativos & 97 & 27,2 \\
\hline \multicolumn{3}{|l|}{ Higiene do coto umbilical } \\
\hline Componente utilizado na higiene & 335 & 93,8 \\
\hline Água e sabão & 214 & 59,9 \\
\hline Álcool a 70\% & 100 & 28 \\
\hline Alternativos & 43 & 11,9 \\
\hline \multicolumn{3}{|l|}{ Manejo das Patologias Comuns } \\
\hline \multicolumn{3}{|l|}{ Conjuntivite } \\
\hline Componente utilizado na higiene & 133 & 37,2 \\
\hline Água & 25 & 18 \\
\hline Alternativos & 108 & 81 \\
\hline \multicolumn{3}{|l|}{ Icterícia } \\
\hline Tratamentos utilizados & 161 & 45 \\
\hline Banho de sol & 64 & 39,7 \\
\hline Fototerapia hospitalar & 41 & 25,4 \\
\hline Componentes alternativos & 56 & 34,6 \\
\hline \multicolumn{3}{|c|}{ Uso de pomada na prevenção de dermatites } \\
\hline Componentes na prevenção* & 233 & 65,2 \\
\hline Vitaminas A, D, E e B5 & 139 & 59,6 \\
\hline Substâncias adstringentes & 133 & 57 \\
\hline Antimicrobianos tópicos & 70 & 30 \\
\hline Pomada à base de Aloe vera & 14 & 5,8 \\
\hline Substâncias anti-umidade & 6 & 2,5 \\
\hline Cólica abdominal & 219 & 61,3 \\
\hline Utilização de chás na cólica & 115 & 52,5 \\
\hline \multicolumn{3}{|l|}{ Chás utilizados* } \\
\hline Camomila & 78 & 67,8 \\
\hline Erva doce & 65 & 56,5 \\
\hline Erva cidreira & 5 & 4,3 \\
\hline Coentro & 5 & 4,3 \\
\hline Poejo & 3 & 2,6 \\
\hline Outros & 7 & 6 \\
\hline
\end{tabular}

*Múltiplo uso

A equipe de enfermagem aparece como principal orientadora nos cuidados com o coto umbilical $(260=72,8 \%$ ). Para a higiene ocular 28,5\% (38) pela enfermagem e $27 \%$ (36) pelo médico (Tabela 3).

Apenas 32,8\% (77) das pomadas foram indicadas por um profissional de saúde e 63,6\% (149) por familiares e pelos próprios pais. Os cuidados com a icterícia foram orientados por $29,7 \%$ (48) dos profissionais de saúde, sendo 19,2\% (31) enfermagem, 10,5\% (17) médico e 44,5\% (72) avós maternos. Aproximadamente $67 \%$ (77) dos avós indicaram chás para cólica abdominal. 
Tabela 3 - Orientadores de cuidados com coto umbilical, higiene ocular, icterícia, uso de pomadas e chás para cólica nos primeiros 42 dias de vida da criança. Londrina, PR, Brasil, 2013

\begin{tabular}{lcccccccccc}
\multicolumn{10}{c}{ Variáveis } \\
\hline Orientadores & Coto umbilical & \multicolumn{1}{c}{ Higiene ocular } & \multicolumn{2}{c}{ Pomadas } & \multicolumn{2}{c}{ Icterícia } & \multicolumn{2}{c}{ Chás para cólica } \\
\cline { 2 - 15 } & $\mathbf{n}$ & $\mathbf{\%}$ & $\mathbf{n}$ & $\mathbf{\%}$ & $\mathbf{n}$ & $\mathbf{\%}$ & $\mathbf{n}$ & $\mathbf{\%}$ & $\mathbf{N}$ & $\mathbf{\%}$ \\
& $\mathbf{3 5 7}$ & $\mathbf{1 0 0}$ & $\mathbf{1 3 3}$ & $\mathbf{1 0 0}$ & $\mathbf{2 3 3}$ & $\mathbf{1 0 0}$ & $\mathbf{1 6 1}$ & $\mathbf{1 0 0}$ & $\mathbf{1 1 5}$ & $\mathbf{1 0 0}$ \\
\hline Enfermagem & 260 & 72,8 & 38 & 28,5 & 13 & 5,5 & 31 & 19,2 & - & - \\
\hline Médico & 43 & 12 & 36 & 27 & 41 & 17,5 & 17 & 10,5 & 4 & 3,4 \\
\hline Avós maternos & 22 & 6,1 & 29 & 21,7 & 16 & 6,8 & 72 & 44,5 & 77 & 66,8 \\
\hline Outro familiar & 23 & 6,1 & 11 & 8,9 & 20 & 8,4 & 21 & 12,9 & 22 & 18,9 \\
\hline Amigas & 7 & 1,9 & 13 & 9,7 & 26 & 11,1 & 7 & 4,3 & 4 & 3,4 \\
\hline Farmacêutico & 2 & 0,5 & 5 & 3,7 & 23 & 9,8 & - & - & - & - \\
\hline Próprios pais & - & - & - & - & 87 & 37,3 & 13 & 8 & 8 & 6,8
\end{tabular}

As variáveis que se apresentaram estatisticamente significativas com a classe social foram faixa etária, escolaridade e renda familiar. A maior porcentagem das mulheres da classe social $A B$ tinha idade acima de 25 anos, ao contrário da CD.

Verifica-se que em ambas as classes sociais as porcentagens foram semelhantes tanto na situação conjugal como na via de parto, peso ao nascer e na rede de apoio familiar. A multiparidade totalizou $70,1 \%$ (47) na classe social $A B$. As mulheres remuneradas $53,7 \%$ pertenciam à classe social $A B$, enquanto que não remuneradas à classe $C D(61,7 \%)$. Os dois grupos referiram que não se adaptaram com tranquilidade nos primeiros 42 dias pós-parto.

Tabela 4 - Variáveis socioeconômicas e rede apoio materno de acordo com a classe social. Londrina, PR, Brasil, 2013 (continua)

\begin{tabular}{|c|c|c|c|c|c|}
\hline \multirow{3}{*}{ Variáveis } & \multicolumn{4}{|c|}{ Classe Social } & \multirow{3}{*}{$\begin{array}{c}\text { Valor } \\
\mathbf{p}\end{array}$} \\
\hline & \multicolumn{2}{|c|}{$\mathbf{A B}$} & \multicolumn{2}{|c|}{ CD } & \\
\hline & $\begin{array}{c}n \\
67 \\
\end{array}$ & $\begin{array}{c}\% \\
100\end{array}$ & $\begin{array}{c}\mathbf{n} \\
290\end{array}$ & $\begin{array}{c}\% \\
100\end{array}$ & \\
\hline \multicolumn{6}{|l|}{ Faixa etária (em anos) } \\
\hline$\leq 24$ & 18 & 26,9 & 163 & 56,2 & \multirow[t]{2}{*}{$<0,0001^{1}$} \\
\hline$\geq 25$ & 49 & 73,1 & 127 & 43,8 & \\
\hline \multicolumn{6}{|c|}{ Escolaridade (anos de estudo) } \\
\hline$\leq 7$ & 8 & 11,9 & 80 & 27,6 & \multirow[t]{2}{*}{$0,007^{1}$} \\
\hline 8 e mais & 59 & 88,1 & 210 & 72,4 & \\
\hline \multicolumn{6}{|l|}{ Situação conjugal } \\
\hline Com companheiro & 59 & 88,1 & 241 & 83,1 & \multirow[t]{2}{*}{$0,36^{1}$} \\
\hline Sem companheiro & 8 & 11,9 & 49 & 16,9 & \\
\hline \multicolumn{6}{|l|}{ Paridade } \\
\hline Primípara & 20 & 29,9 & 123 & 42,4 & \multirow[t]{2}{*}{$0,072^{1}$} \\
\hline Multípara & 47 & 70,1 & 167 & 57,6 & \\
\hline \multicolumn{6}{|l|}{ Ocupação materna } \\
\hline Remunerada & 36 & 53,7 & 111 & 38,3 & \multirow[t]{2}{*}{$0,027^{1}$} \\
\hline Não remunerada & 31 & 46,3 & 179 & 61,7 & \\
\hline \multicolumn{6}{|l|}{ Via de parto } \\
\hline Vaginal & 47 & 70,1 & 219 & 75,5 & \multirow[t]{2}{*}{$0,356^{1}$} \\
\hline Cirúrgico & 20 & 29,9 & 71 & 24,5 & \\
\hline
\end{tabular}




\begin{tabular}{lccccc}
\hline Peso ao nascer (em gramas) & & & \\
\hline$<2500$ & 1 & 1,5 & 5 & 1,7 & $1,000^{1}$ \\
\hline$\geq 2500$ & 66 & 98,5 & 285 & 98,3 \\
\hline Rede apoio no retorno para casa & & & & & \\
\hline Sim & 66 & 98,5 & 283 & 97,6 \\
\hline Não & 1 & 1,5 & 7 & 2,4 & $1,000^{1}$ \\
\hline Adaptação no período foi tranquila & & & & & \\
\hline Sim & 30 & 44,8 & 139 & 47,9 & $0,685^{1}$ \\
\hline Não & 37 & 55,2 & 151 & 52,1
\end{tabular}

${ }^{1}$ Teste Exato de Fischer.

O uso de componentes alternativos no cuidado da criança foi mais frequente na classe social CD no banho, higiene coto umbilical, na conjuntivite e icterícia, embora não tenha apresentado associação estatística.

O uso do chá para cólica apresentou relação estatística com a classe social e verifica-se que a CD foi mais frequente $(98=57 \%)$, sendo a erva-doce e camomila as mais utilizadas. A quase totalidade dos cuidados da criança com relação à conjuntivite, icterícia, dermatites e manejo da cólica abdominal foram orientados pelos familiares em ambas as classes.

Tabela 5 - Cuidados maternos na higiene corporal, manejo das patologias comuns e respectivos orientadores de acordo com a classe social. Londrina, PR, Brasil, 2013 (continua)

\begin{tabular}{|c|c|c|c|c|c|}
\hline \multirow{3}{*}{ Variáveis } & \multicolumn{4}{|c|}{ Classe Social } & \multirow{3}{*}{$\begin{array}{l}\text { Valor } \\
\text { de } p\end{array}$} \\
\hline & \multicolumn{2}{|c|}{$\mathbf{A B}$} & \multicolumn{2}{|c|}{ CD } & \\
\hline & $\begin{array}{l}n \\
67\end{array}$ & $\begin{array}{c}\% \\
100\end{array}$ & $\begin{array}{c}n \\
290\end{array}$ & $\begin{array}{c}\% \\
100\end{array}$ & \\
\hline \multicolumn{6}{|l|}{ Componente utilizado no banho } \\
\hline Água e sabão & 57 & 85,1 & 230 & 81,3 & $0,596^{1}$ \\
\hline Alternativos & 10 & 14,9 & 53 & 18,7 & \\
\hline \multicolumn{6}{|l|}{ Componente higiene do coto umbilical } \\
\hline Água e sabão & 47 & 72,3 & 178 & 63,3 & $0,194^{1}$ \\
\hline Álcool a $70 \%$ & 18 & 27,7 & 94 & 33,5 & \\
\hline Alternativos & - & & 9 & 3,2 & \\
\hline \multicolumn{6}{|c|}{ Orientadores do cuidado do coto umbilical } \\
\hline Familiares/conhecidos & - & - & 34 & 12,7 & $0,010^{2}$ \\
\hline Profissionais de saúde & 65 & 100 & 234 & 87,3 & \\
\hline \multicolumn{6}{|l|}{ Componente para conjuntivite } \\
\hline Água & 18 & 74 & 51 & 51,5 & $0,053^{2}$ \\
\hline Alternativos & 6 & 25 & 48 & 48,5 & \\
\hline \multicolumn{6}{|l|}{ Orientadores do cuidado da conjuntivite } \\
\hline Familiares/conhecidos & 8 & 72,7 & 33 & 51,6 & $0,326^{1}$ \\
\hline Profissionais de saúde & 3 & 27,3 & 31 & 48,4 & \\
\hline \multicolumn{6}{|l|}{ Tratamentos utilizados para Icterícia } \\
\hline Banho de sol e fototerapia & 20 & 55,6 & 68 & 54,4 & $0,883^{2}$ \\
\hline Componentes alternativos no banho & 16 & 44,5 & 57 & 45,6 & \\
\hline
\end{tabular}




\begin{tabular}{|c|c|c|c|c|c|}
\hline \multicolumn{6}{|c|}{ Orientadores do cuidado da icterícia } \\
\hline Familiares/conhecidos & 30 & 85,7 & 102 & 85 & $1,000^{1}$ \\
\hline Profissionais de saúde & 5 & 14,3 & 18 & 15 & \\
\hline \multicolumn{6}{|c|}{ Pomada na prevenção de dermatites } \\
\hline Sim & 52 & 77,6 & 180 & 62,1 & $0,016^{1}$ \\
\hline Não & 15 & 22,4 & 110 & 37,9 & \\
\hline \multicolumn{6}{|c|}{ Orientadores do uso de pomadas } \\
\hline Familiares/conhecidos & 31 & 60,7 & 126 & 71,2 & $0,279^{2}$ \\
\hline Profissionais de saúde & 20 & 39,2 & 51 & 28,8 & \\
\hline \multicolumn{6}{|l|}{ Uso chás para cólica } \\
\hline Sim & 16 & 34,8 & 98 & 57 & $0,008^{1}$ \\
\hline Não & 30 & 65,2 & 74 & 43 & \\
\hline \multicolumn{6}{|l|}{ Tipos de chás } \\
\hline Erva doce/Camomila & 18 & 94,7 & 111 & 88,1 & $0,011^{2}$ \\
\hline Outros & 1 & 5,3 & 15 & 11,9 & \\
\hline \multicolumn{6}{|c|}{ Orientadores do uso de chás } \\
\hline Familiares/conhecidos & 18 & 100 & 121 & 96,8 & $0,741^{2}$ \\
\hline Profissionais de saúde & - & & 4 & 3,2 & \\
\hline \multicolumn{6}{|c|}{ Orientadores da massagem para cólicas } \\
\hline Familiares/conhecidos & 27 & 71,1 & 103 & 64,2 & $0,728^{2}$ \\
\hline Profissionais de saúde & 11 & 28,9 & 48 & 31,8 & \\
\hline
\end{tabular}

${ }^{1}$ Teste Exato de Fischer; ${ }^{2}$ Teste Q-quadrado.

\section{DISCUSSÃO}

Cada grupo social é representado por práticas que se perpetuam entre as gerações ${ }^{(6-7)}$ e, embora a ciência comprove que algumas não são benéficas e na atualidade haja ampla disponibilidade de informação, ainda assim, são preservadas no núcleo familiar. A perpetuação destas práticas também depende das condições sociais, escolaridade, faixa etária, bem como ao acesso aos serviços de saúde de qualidade, variáveis que se apresentaram estatisticamente significativas no presente estudo. Portanto, é fundamental que a equipe de saúde ${ }^{(5)}$ desmitifique tabus, mitos e crenças no intuito de diminuir riscos à saúde da criança.

Diante do nascimento de uma criança e de todos os cuidados que ela demanda, torna-se comum o medo e a dúvida, principalmente entre primíparas, sendo recorrente o auxílio de familiares ${ }^{(4)}$. A adaptação ao cotidiano pós-parto nas duas classes foi com dificuldade, embora houvesse apoio familiar. Neste aspecto, é necessário conhecer e compreender a maneira como a família cuida ${ }^{(9)}$ e cabe ao profissional de saúde orientá-la, detectando precocemente qualquer prática incorreta e suas possíveis complicações.

O uso das terapias alternativas no presente estudo foi comum para o cuidado da criança tanto no banho quanto para a conjuntivite, icterícia, dermatites e cólica, orientada predominantemente por avós, reafirmando os resultados de pesquisas quanto à influência na perpetuação de práticas que cientificamente são consideradas prejudiciais à saúde ${ }^{(5-7)}$. Apenas orientações no cuidado com coto umbilical foram realizadas pelos profissionais de saúde, entre eles a enfermagem.

No que se refere à higiene do recém-nascido, o banho tem sido uma das dificuldades maternas, em especial no pré-termo ou primeiro filho. Portanto, o sistema de Alojamento Conjunto possibilita um momento de auxílio e orientações da equipe de enfermagem ${ }^{(10)}$. Neste estudo, algumas mães delegaram o banho a outras pessoas de seu convívio. Pesquisa identificou que $69,3 \%$ das puérperas desconheciam os produtos, frequência, sequência do banho e temperatura ideal da água, necessitando 
de apoio familiar ${ }^{(9)}$.

Outra pesquisa identificou os principais receios maternos com o banho do bebê, como medo em deixar cair água no ouvido, manipular o coto umbilical, limpar a genitália e queda de sabão nos olhos. Também faziam ampla utilização de ervas medicinais típicas da região, na água do banho, cura de resfriados, tosse e cólicas intestinais ${ }^{(11)}$.

Estudo mostra efeitos adversos dos chás, como bradicardia, hipoglicemia, queimadura de pele e aumento da secreção em vias aéreas ${ }^{(12)}$. No presente estudo, o uso de componentes alternativos foi mais frequente entre a classe social CD e a camomila foi a mais frequente, embora contraindicada para menores de um ano de vida, assim como qualquer outra erva, devido ao risco de ingestões de esporos da bactéria Clostridium botulinum ${ }^{(12-13)}$.

A higiene do coto umbilical, assim como o banho do recém-nascido, muitas vezes é delegada a outras pessoas do convívio, devido ao medo de manuseá-lo. Apesar de muitas maternidades orientarem este cuidado ainda no alojamento conjunto, algumas vezes esta ação não é executada no domicílio, onde acabam por aderir a práticas intergeracionais que podem ser agravantes à saúde da criança, por exemplo favorecendo infecções ${ }^{(14)}$.

Os componentes mais utilizados no Brasil para a higiene do coto umbilical são a água e sabão e o álcool $70 \%$, evidenciados nos resultados da presente pesquisa. Além destes, o uso de outras substâncias e objetos no coto, como moedas, fumo e faixas, também foram condizentes com pesquisas em outras regiões do país, prática nacional que atravessa gerações e que pode trazer danos ao bebê, como a onfalite ${ }^{(14-17)}$. Este estudo, embora não tenha apresentado associação estatística entre o uso de componentes alternativos e classe social, verificou-se que estes foram utilizados em maior frequência pela CD.

No que se refere à conjuntivite, o tratamento no presente estudo foi o leite materno e quase a metade entre as mulheres da classe social $C D$, embora presente na $A B$ em menor frequência. Esta infecção sem avaliação adequada pode acarretar prejuízo se não tratada corretamente com colírios, pois pode estar relacionada à obstrução do canal lacrimal, contaminação adquirida durante o parto vaginal e reação pelo nitrato de prata $1 \%{ }^{(18-20)}$.

Outro agravo comum no período neonatal é a icterícia fisiológica, as mães por estarem em casa e não querer retornar ao hospital realizam cuidados alternativos como meio de cura, como banho de picão somado à ingesta do chá(21), resultado semelhante no presente estudo pouco mais frequente na classe $\mathrm{CD}$, indicada pelos avós. Autores referem que não foi encontrada nenhuma ação tóxica no picão, mas não recomendam o consumo entre menores de um ano de idade, devido ao risco de contaminação ${ }^{(21)}$.

Quanto aos cuidados com a pele do neonato, mães fazem uso indiscriminado de pomadas para prevenir dermatites ${ }^{(22)}$ como entre as mulheres deste estudo, indiferentemente da classe social, indicado por familiares. Embora seja comum o uso de soluções emolientes para manter a integridade da pele, não há estudos comprovando sua eficácia ${ }^{(22-23)}$, mas deve-se considerar que os aditivos da composição podem causar sensibilização de contato, irritação e toxicidade ao bebê( ${ }^{(24)}$.

Uma das principais dificuldades referidas por mães no presente estudo foi a cólica abdominal e, para o alívio, fizeram uso de chás indicado pelos avós. Autor aponta que pais, por insegurança e inexperiência, acabam se apoiando na vivência e tradição de familiares e realizam práticas duvidosas e até prejudiciais ao bebê, como o uso indiscriminado de medicações e chás de ervas, que além de interferir no aleitamento materno, podem causar toxicidade e infecções intestinais ${ }^{(1)}$.

Esta prática ocorre em diversos lugares do Brasil, sendo a camomila a mais utilizada desde os primeiros dias de vida, mais comum entre mães adolescentes que coabitam com avó materna ${ }^{(25)}$. $\mathrm{Na}$ análise microbiológica de cinco amostras de sachês de camomila, comercializadas em Curitiba-PR, provenientes de ervanários, farmácias e supermercados, todas foram reprovadas em relação ao teor de fungos e leveduras, duas foram pela quantidade de coliformes totais e presença de Salmonella, que implica riscos à saúde ${ }^{(26)}$.

A equipe de saúde tem um papel importante, principalmente no preparo dos pais, ainda na maternidade, pois os primeiros meses da criança são um momento frágil, principalmente para a mãe, mediante o sentimento de incompetência e falta de controle para o alívio da dor ${ }^{(1)}$. 
Este estudo teve como limitação as informações sobre o cuidado da criança terem como base o relato materno. Sugere-se a realização de estudos que possam investigar a perspectiva de profissionais de saúde, bem como familiares.

\section{- CONCLUSÃO}

O uso de terapia complementar ocorreu entre as mães no cuidado da criança durante os primeiros 42 dias de vida, frequentemente orientadas pelos avós, ao contrário da participação dos profissionais de saúde. Apesar da facilidade de acesso às informações e aos serviços de saúde, tais práticas se mantiveram entre as gerações, mais comumente entre a classe social CD.

Conhecendo-se os malefícios decorrentes desta prática, cabe aos profissionais de saúde, em especial à equipe de enfermagem que atua diretamente neste grupo etário e família, detectar e intervir precocemente para evitar injúrias à criança. Tal intervenção deve considerar os aspectos culturais dos membros desta família na assistência durante o acompanhamento, seja na consulta na unidade ou na visita domiciliar, bem como evitar menosprezar conhecimentos que se perpetuam entre as gerações, devido ao risco das orientações não promoverem a saúde e prevenirem agravos.

\section{REFERÊNCIAS}

1. Iserhard ARM, Budó MLD, Neves ET, Badke MR. Práticas culturais de cuidados de mulheres mães de recémnascidos de risco do sul do Brasil. Esc Anna Nery. [Internet] 2009 [acesso em 2016 jun 04]; 13(1). Disponível em: http://www.scielo.br/scielo.php?script=sci_issuetoc\&pid=1414-814520090001\&lng=pt\&nrm=1.

2. Tomeleri KR, Marcon SS. Práticas populares de mães adolescentes no cuidado aos filhos. Acta paul. enferm. [Internet] 2009 [acesso em 2016 jun 04]; 22(3). Disponível em: http://dx.doi.org/10.1590/S0103-21002009000300006.

3. Vieira VCL, Fernandes CA, Demitto MO, Bercini LO, Scochi MJ, Marcon SS. Puericultura na atenção primária à saúde: atuação do enfermeiro. Cogitare enferm. [Internet] 2012 [acesso em 2016 abr 30];17(1). Disponível em: http://dx.doi.org/10.5380/ce.v17i1.26384.

4. Gentil LB, Robles ACC, Grosseman S. Uso de terapias complementares por mães em seus filhos: estudo em um hospital universitário. Ciênc. saúde coletiva. [Internet] 2010;15(Suppl 1) [acesso em 15 abr 2016]. Disponível: http://dx.doi.org/10.1590/S1413-81232010000700038.

5. Seima MD, Michel T, Méier MJ, Wall ML, Lenardt MH. A produção científica da enfermagem e a utilização da teoria de Madeleine Leininger: revisão integrativa 1985-2011. Esc. Anna Nery. [Internet] 2011 [acesso em 2016 abr 15]; 15(4). Disponível: http://www.readcube.com/articles/10.1590/s1414-81452011000400027.

6. Silva JAP e, Freire DG, Machado MFA. Cuidados maternos à saúde da criança em ambiente domiciliar frente ao serviço de saúde. Rev Rene. [Internet] 2010 [acesso em 2016 abr 15]; 11(n.esp). Disponível em: http://www. revistarene.ufc.br/revista/index.php/revista/issue/view/27.

7. Badke MR, Budó MLD, Alvim NAT, Zanetti GD, Heisler EV. Saberes e práticas populares de cuidado em saúde com o uso de plantas medicinais. Texto contexto - enferm. [Internet] 2012 [acesso em 2016 mar 11]; 21(2). Disponível em: http://dx.doi.org/10.1590/S0104-07072012000200014.

8. Associação Brasileira de Empresas de Pesquisa (ABEP). Dados com base no Levantamento Sócio Econômico 2012. [Internet] 2015 acesso em 2016 maio 10]. Disponivel em: file://C:/Users/HP/Downloads/09_cceb_2014\%20 (2).pdf 
9. Andrade LCO, Santos MS dos, Aires JS, Joventino ES, Dodt RCM, Ximenes LB. Conhecimento de puérperas internadas em um alojamento conjunto acerca da higiene do neonato. Cogitare enferm. [Internet] 2012 [acesso em 20163 maio 10]; 17(1). Disponível em: http://dx.doi.org/10.5380/ce.v17i1.26381.

10. Brasil. Ministério da Saúde. Portaria n. 1.016, de 26 de agosto de 1993. Aprova as normas básicas para a implantação do sistema "Alojamento Conjunto". Diário Oficial da União. Brasília, 26 ago 1993.

11. Maia SMS, Silva LR da. Saberes e práticas de mães ribeirinhas e o cuidado dos filhos recém-nascidos: contribuição para a enfermagem. Rev. Enf. Ref. [Internet] 2012 [acesso em 2017 fev 3]; 3(7). Disponível em: http:// dx.doi.org/10.12707/RIII11130.

12. Malveiro D, Henriques C, Flores P, Barata D, Vieira JP, Cabral P. Botulismo Infantil em Portugal: um lactente com hipotonia. Acta Ped Portuguesa. [Internet] 2013 [acesso em 2016 maio 20]; 44(4). Disponível em: http:// actapediatrica.spp.pt/article/viewFile/2659/2679.

13. Cagan E, Peker E, Dogan M, Caksen H. Infant botulism. Eurasian J Med. [Internet] 2010 [acesso em 2016 maio 20]; 42(2). Disponível em: http://dx.doi.org/10.5152/eajm.2010.25.

14. Ribeiro MB, Brandão MNM. A produção científica da enfermagem sobre coto umbilical. Rev Interdisciplinar NOVAFAPI. [Internet] 2011 [acesso em 2016 ago 20]; 4(3). Disponível em: http://uninovafapi.edu.br/sistemas/ revistainterdisciplinar/v4n3/v4n3.html.

15. Carmo AML do, Oliveira LN de. O papel do enfermeiro na prevenção da onfalite e seus principais aspectos em saúde. Rev Enferm UNISA. [Internet] 2009 [acesso em 2016 ago 20]; 10(2). Disponível em: http://w2.unisa.br/ graduacao/biologicas/enfer/revista/volumes/2009-2.shtml.

16. Linhares EF, Silva LWS da, Rodrigues VP, de Araújo RT. Influência intergeracional no cuidado do coto umbilical do recém-nascido. Texto contexto - enferm. [Internet] 2012 [acesso em 2016 abr 16]; 21(4). Disponível em: http:// dx.doi.org/10.1590/S0104-07072012000400013.

17. Souza RS de, Ferrari RAP, Santos TFM, Tacla MTGM. Atenção à saúde da criança: prática de enfermeiros da saúde da família. Rev Min Enferm. [Internet] 2013 [acesso em 2016 abr 16]; 17(2). Disponível em: http://www. dx.doi.org/10.5935/1415-2762.20130025.

18. Azzolini TF, Leinig CAS. Correlação entre a pesquisa laboratorial de Neisseria gonorrhoeae e Chlamydia trachomatis com sua apresentação clínica. Rev Fepar. [Internet] 2011 [acesso em 2016 abr 02]; 1(1). Disponível em: http://www.fepar.edu.br/revistaeletronica/index.php/revfepar/article/view/13/13.

19. Costa MC, Demarch EB, Azulay DR, Perissé ARS, Dias MFRG, Nery JAC. Doenças sexualmente transmissíveis na gestação: uma síntese de particularidades. An. Bras. Dermatol. [Internet] 2010 [acesso em 2016 fev 02]; 85(6). Disponível em: http://dx.doi.org/10.1590/S0365-05962010000600002.

20. Passos AF, Agostini FS. Conjuntivite neonatal com ênfase na sua prevenção. Rev bras. oftalmol. [Internet] 2011 [acesso em 2016 fev 15]; 70(1). Disponível em: http://dx.doi.org/10.1590/S0034-72802011000100012.

21. Luchesi BM, Beretta MIR, Dupas G. Conhecimento e uso de tratamentos alternativos para a icterícia neonatal. Cogitare enferm. [Internet] 2010 [acesso em 2016 fev 15]; 15(3). Disponível em: http://dx.doi.org/10.5380/ ce.v15i3.18896.

22. Fontanele FC, Cardoso MVLML. Lesões de pele em recém-nascidos no ambiente hospitalar: tipo, tamanho e área afetada. Rev esc. enferm. USP. [Internet] 2011 [acesso em 2016 mar 17]; 45(1). Disponível em: http://dx.doi. 
org/10.1590/S0080-62342011000100018.

23. Duarte AS, Santos WS, Silva LDB, Oliveira JD, Sampaio KJAJ. Promoção de saúde às genitoras de bebês prematuros: ação da enfermagem na alta hospitalar. Rev Rene. [Internet] 2010 [acesso em 2016 mar 17]; 11(3). Disponível em: http://www.revistarene.ufc.br/vol11n3_html_site/a17v11n3.html.

24. Fernandes JD, Machado MCR, de Oliveira ZNP. Quadro clínico e tratamento da dermatite da área de fraldasParte II. An. Bras. Dermatol. [Internet] 2009 [acesso em 2016 maio 10]; 84(1). Disponível em: http://dx.doi. org/10.1590/S0365-05962009000100007.

25. Kimura AF, Silva IA, Tsunechiro MA, Siqueira FPC, Bueno M, Lima MOP, et al. A saúde neonatal na perspectiva de atenção contínua à saúde da mulher e da criança. Rev esc. enferm. USP. [Internet] 2009 [acesso em 2016 maio 10]; 43(2). Disponível em: http://www.scielo.br/scielo.php?script=sci_issuetoc\&pid=0080$623420090002 \& \operatorname{lng}=$ pt\&nrm=iso.

26. Rodrigues JD, de Lima CP. Análise microbiológica e físico-química de amostras secas de camomila, Matricariarecutita, asteraceae, comercializadas em Curitiba, Paraná. Cad da Esc de Saúde. [Internet] 2015acesso em 2016 maio 10]; 2(14). Disponível em: http://portaldeperiodicos.unibrasil.com.br/index.php/cadernossaude/ article/viewFile/2438/2008. 